\title{
Cultural landscapes and troy; an old Anatolian settlement
}

\author{
Aysel Uslu* - Elmas Erdogan - Zuhal Dilaver \\ Ankara University, Faculty of Agriculture, \\ Department of Landscape Architecture, Diskapı, 06110, Ankara TURKIYE \\ Phone: +90 3125961732 Fax: +90 3123176467 \\ *Correspondening Author Email: uslu@agri.ankara.edu.tr
}

\begin{abstract}
Troy which is located on the straits dividing the continents of Europe and Asia have retained its geographical significance till prehistoric times. Troia/Troy/Truva was excavated by Schliemann, Dörpfeld and Blegen. Troy mound was formed of a series of fortified settlements built one upon another. Not only the site of Troy itself, but also the surrounding terrain has played an important role in the cultural history of mankind. It has been also one of the best known landscapes in the world since prehistoric times. According to the data obtained from the excavations, the city of Troy must have comprised a total at least $200000 \mathrm{~m} 2$, ranking it as one of the largest cities of its period within western Anatolia and Eagean realm. Due to the calculations based on area occupied and productivity of the region, reach about 6000-7000 inhabitants. In view of the increasing assets of natural and cultural heritage of the area, the proposals to take care of the Troy, to protect the surrounding landscape and establish a historic national park have received national support. Association with the national park of Gallipoli (Canakkale) Peninsula on the other side of Dardanelles in an integrated planning approach can be a good solution both for the protection and the sustainability of the area. In this article, the city of Troy as one of the best examples of prehistoric settlements of Anatolia was presented. Troy and its near environs was introduced with its natural, historical and cultural aspects. Settlement formation, urban development, building types, construction material and techniques, spatial organizations in the urban fabric were discussed for different layers of the settlement. And the present situation of the area was analyzed in the frame of cultural landscapes and landscape qualities.
\end{abstract}

\section{TROY}

Keywords: Anatolia, Troy, Dardanelles, cultural landscapes, archeological sites, cultural heritage, conservation

Troy which is a legendary settlement that was described in Iliad is in Hisarlık in Canakkale province in northwest Turkey, under Mount Ida. Today, the layers of the ruins in the citadel at Hisarlık are 9 layers and the archeological site of Troy was added to the UNESCO World Heritage List in 1998.

The first city of Troy was founded in 3000 B.C. and became a flourished mercantile city during the Bronze Age since its location allowed an identifiable control of the Dardanelles and Canakkale region. Troy I was demolished in the year 2500 B.C. and Troy II that was founded in its place was brought to its end by a fire in 2300 B.C. Then, Troy III. IV, V were founded and Troy VI was founded between the years 1800- 1275 B.C. whose city walls are still existing today. Troy VII is the stratum where the famous Trojan War took place in 1200 B.C. (3).

Troy VI was destroyed around 1300 B.C. by an earthquake whereas Troy VII was destroyed by war
(2). Troy IX is the last city on the archeological site that was founded by the Romans during the reign of Augustus and was an important trade center till the establishment of Constantinople in the 4th. C., A.D. as the eastern capital of the Roman Empire so, the city was declined gradually during the Byzantine Period and disappeared eventually. Many excavations were made in this archeological settlement since 1868 by different German archeological teams (2). The site has been frequently excavated, so that these unsafe and unsensitive applications demolished many interesting structures taking place in different layers of the settlement. In the Bronze Age, Troy had a great power because of its strategic location between Europe and Asia and the city was a cultural center in the $3 \mathrm{rd}$. and $2 \mathrm{nd}$. Millennium B.C.

Troy appeared in Greek and Latin literature Homer firs mentioned the story of Troy in Iliad and Odyssey. Troy which is located in northeast Turkey at distance of $30 \mathrm{~km}$. far from the Dardanelles is one of the 
oldest and most famous archeological sites both at national and international levels. The settlement mound of Troy is situated in a strategic position between the two continents in Dardanelles on a lime stone plateau favoring trade and cultural contacts.
This archeological site reflects the traces of 3500 years of habitation. The architectural characteristics of the settlement, differs from that of the Aegean region and Greece (Figure 1).

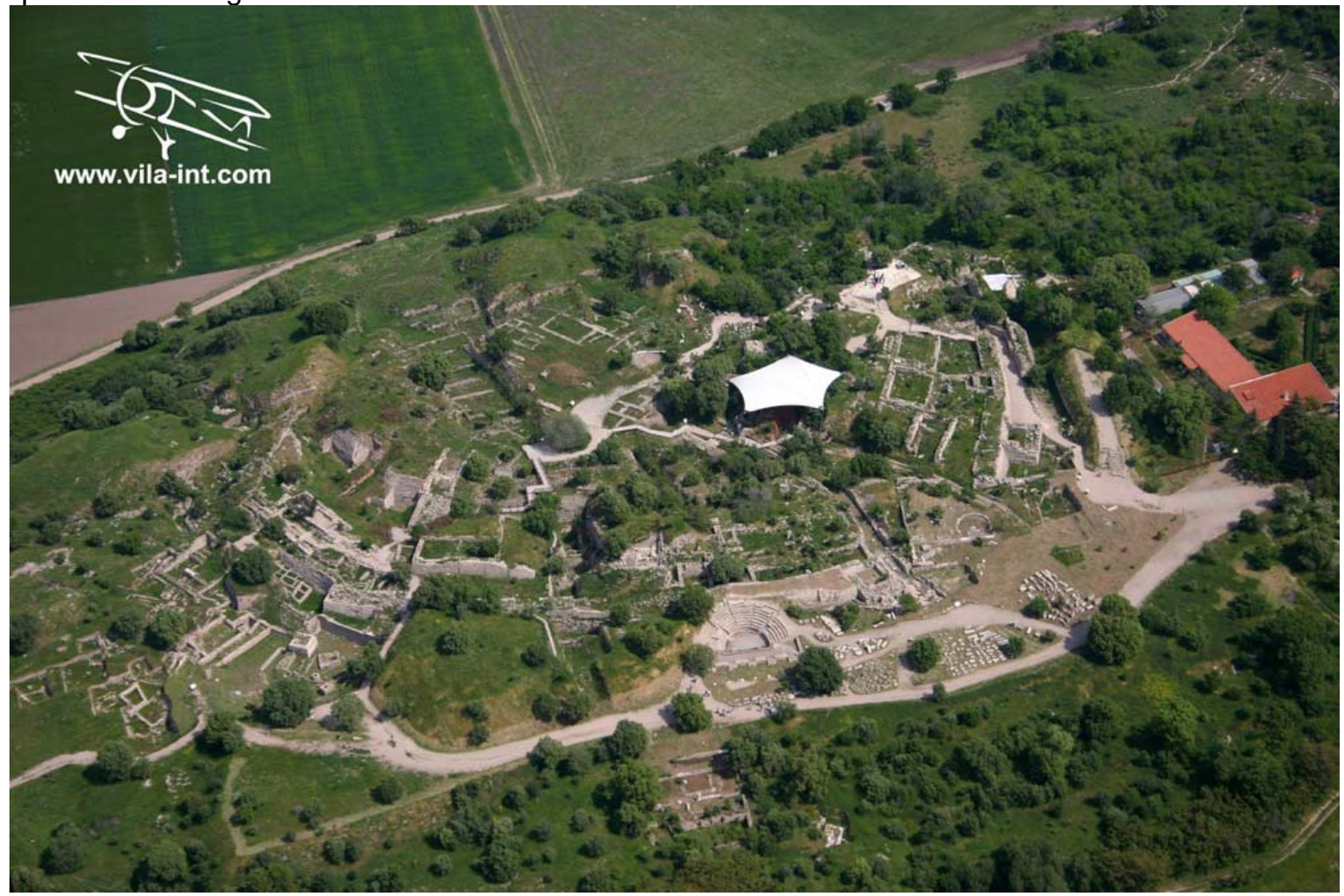

Fig 1. General Layout of Troy (4)

Troy I (3000-2500 B.C.), settlement which consists 10 layers lying one on top the other occupies a small area with a diameter of 90 meters (1) whose city walls are still existing today.

Troy II (2500-2200 B.C.) which consists seven layers of settlements has played an important role in the history of Troy. Although Troy I was destroyed catastrophically, there is no break in the time sequence or culture between the two settlements (1). This layer also gives information about the pattern of the city development. The megaron types of buildings were used in the whole settlement either used as houses or temples. Troy III-V (2200-1800) strata compromises, original construction techniques and house plan schemes built with cut stone masonry.
Troy VI carries a high standart of craftsmanship, however it is seen that the surrounding wall of this settlement strata is small. The ruins and foundations of temples, palaces and houses that are existing show the traces of an extraordinary city development (Figure 2).

The ruins of the houses are preserved well in the layer of Troy VII (1300-1260 B.C.). No trace of Hellenistic civilization is found in Troy VIII (1). On the other hand, some developed temple plans are seen in Troy IX. A great number of Roman remains are existing in this strata, such as the Temple of Athena, the bouleterion, the theater, the auditorium and the city walls (Figure 3 ). 
Agric. Biol. J. N. Am., 2010, 1(3): 395-401

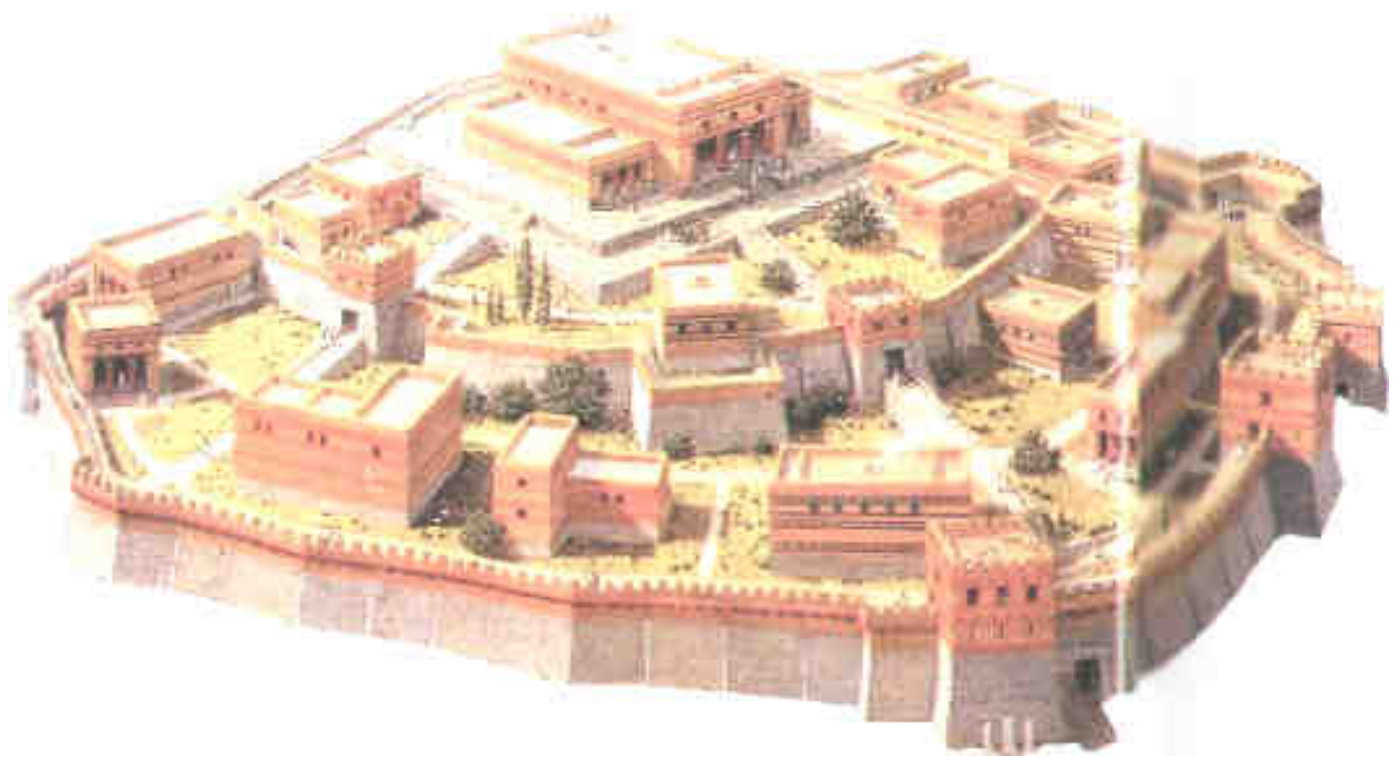

Fig 2. Reconstruction of Troy (5)

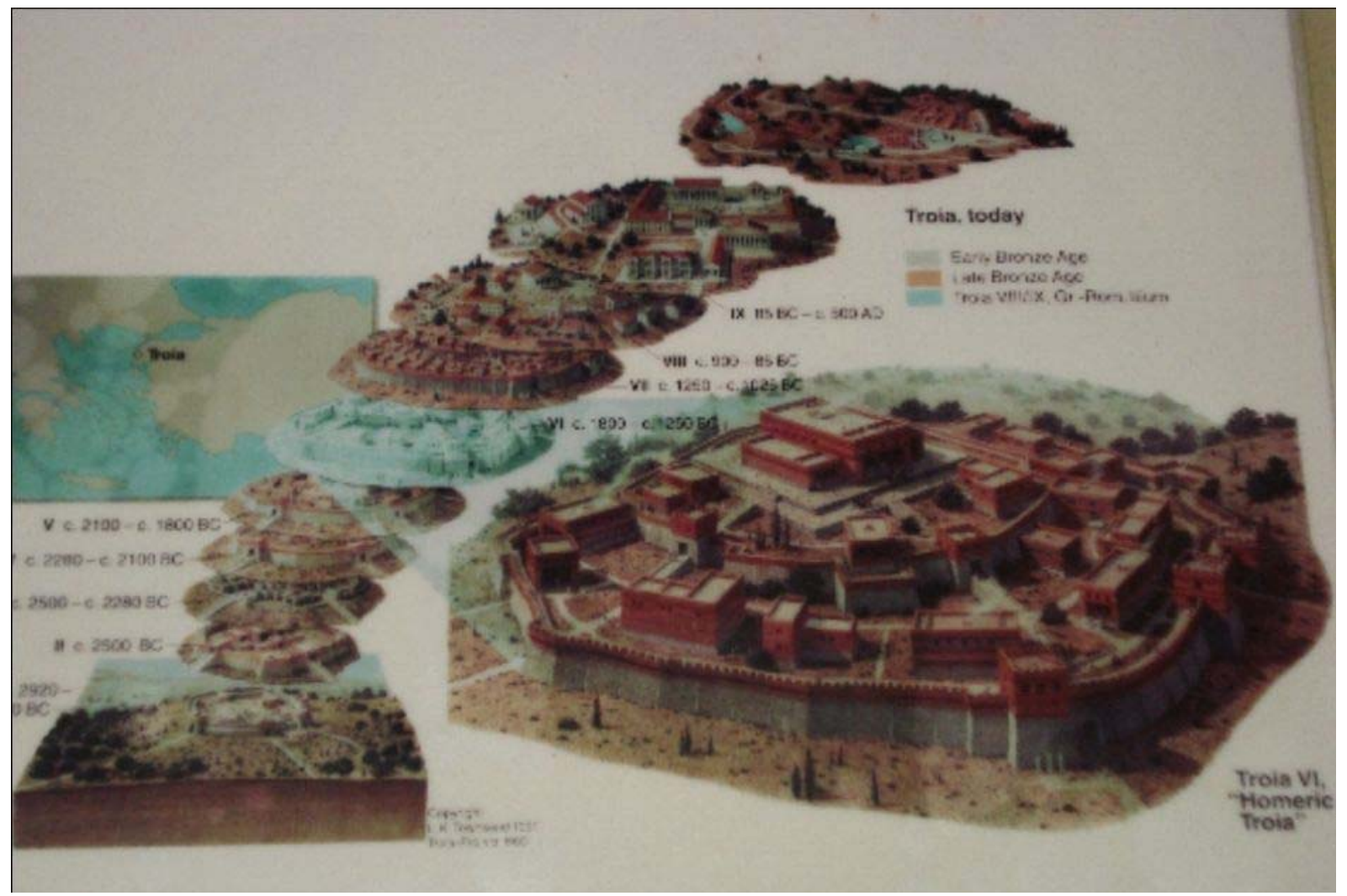

Fig 3. 9 layers in the settlement of Troy (6).

Its fortification walls with stone foundations and mudbrick superstructure formed an impressive earthwork landscape. Although there were similar settlement patterns in Anatolia, comparison with sites in the Aegean realm it was obvious that Troy was the largest city both in the middle and late bronze ages. Troy stands out as an exception in the Anatolian context. The city plan of Troy finds its analogies in the contemporary cities and fortifications of Anatolia and north Syria in the middle and late bronze ages. 
Troy has 9 building periods. According to the archeological excavations, a burnt layer belonging to the second building period carries the traces of Trojan war showing also the strategical importance of the settlement. The most brillant period of Troy was about 1425 to 1300 B.C. and the most impressive remains of the city are the fortifications of Troy $\mathrm{VI}$ which were built during this period. Besides, the remains of megaron type of houses, shrines, temples and storages are giving information about the planning approaches and construction techniques of the period. On the other hand, Troy was also used during Hellenistic and Roman times. A large number of Roman remains also exist in the open area between the city walls and the Temple of Athena (Figure 4).

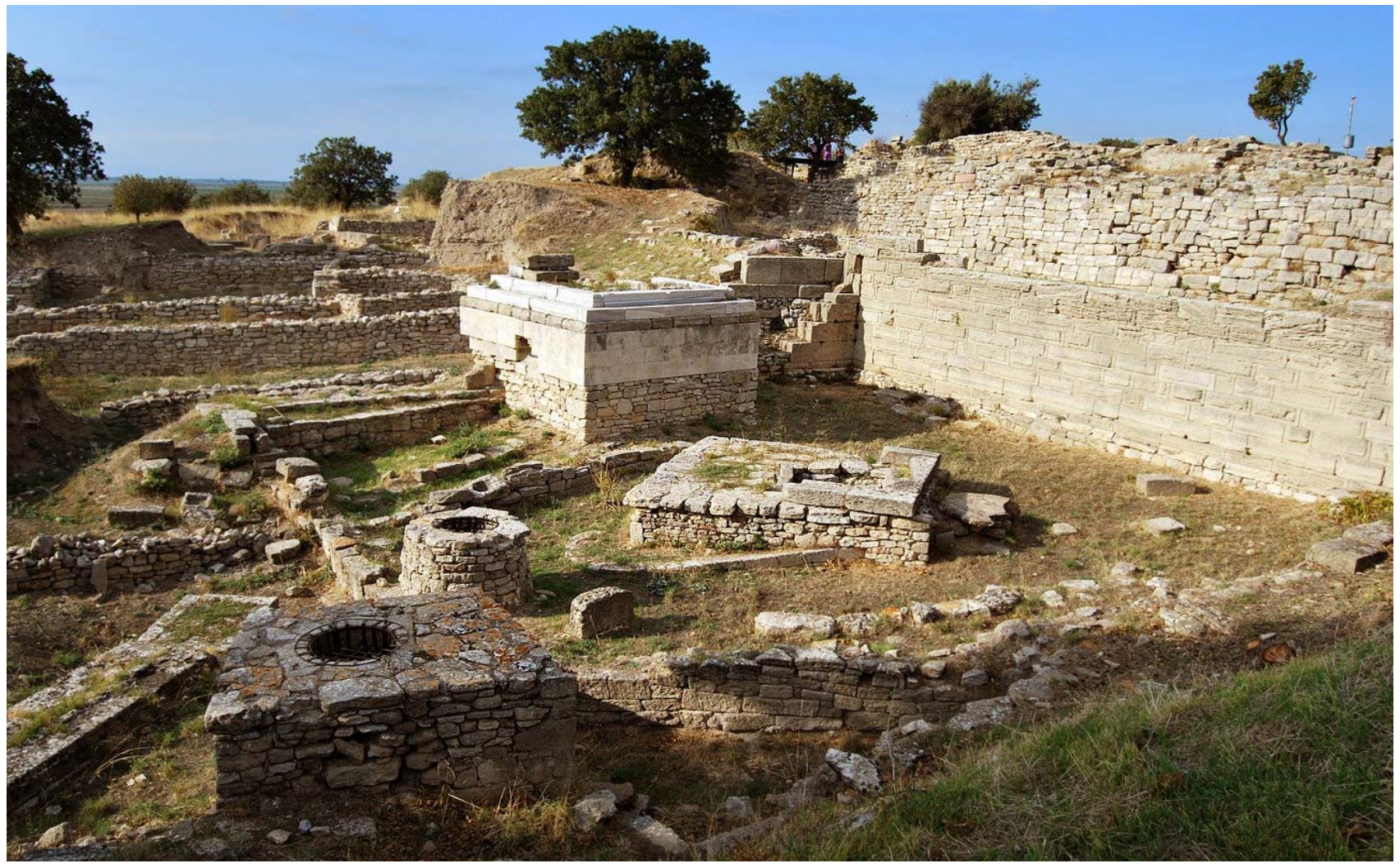

Fig 4. Troy ( Original, 2008)

\section{CULTURAL LANDSCAPES AND CONSERVATION} ISSUES: Landscape is the basic subject of geographical research as a living and changing environment; as the habitat of everyone. It is nature, habitat, artifacts, culture, property, history, aesthetics and a place: a mosaic of the Earth. It is a complete structure combining nature, culture, living and not living; a continuously changing physical image. Landscape is nature, a habitat, a system, a property and history; in brief it is covering all of these components as a complete structure. On the other hand, cultural landscapes are very important resources for countries and especially for the identity of settlements and in the formation of cityscapes. A geographical area including natural and cultural resources and the wildlife associated with a historic event, activity or other cultural-aesthetic values is a cultural landscape. In general, there are four types of cultural landscapes namely historic sites, historic designed landscapes, historic vernacular landscapes and ethnographic landscapes.

Cultural landscapes are the works of man or combined work of nature and of man and areas including archeological sites which are of outstanding universal value from the historical, aesthetic, cultural or anthropological points of view.

Historic archeological sources in cultural landscapes above and below the ground level are important cultural heritages that have to be transferred to future generations. These resources not only have historical value, but can also reveal significant information about a civilization or lives of past cultures and civilizations (8). 
Cultural landscape quality of Troy and its environs are very rich. It is reflecting a rare combination of nature and archeological value of cultural traditions and a settlement pattern of prehistoric and Bronze Age cities in 9 layers having local, regional, national and international importance. The surroundings of cultural landscapes contribute to their significance and their archeological character should be considered prior to treatment. However, change is inherent in cultural landscapes resulting from both natural processes and human activities. So, the integration of cultural landscapes to the existing physical condition is another important factor. In this context, the definition of existing conditions is of prior importance. New uses have to be adopted within the current form of existing landscape and the other features of the environment (Figure 5).

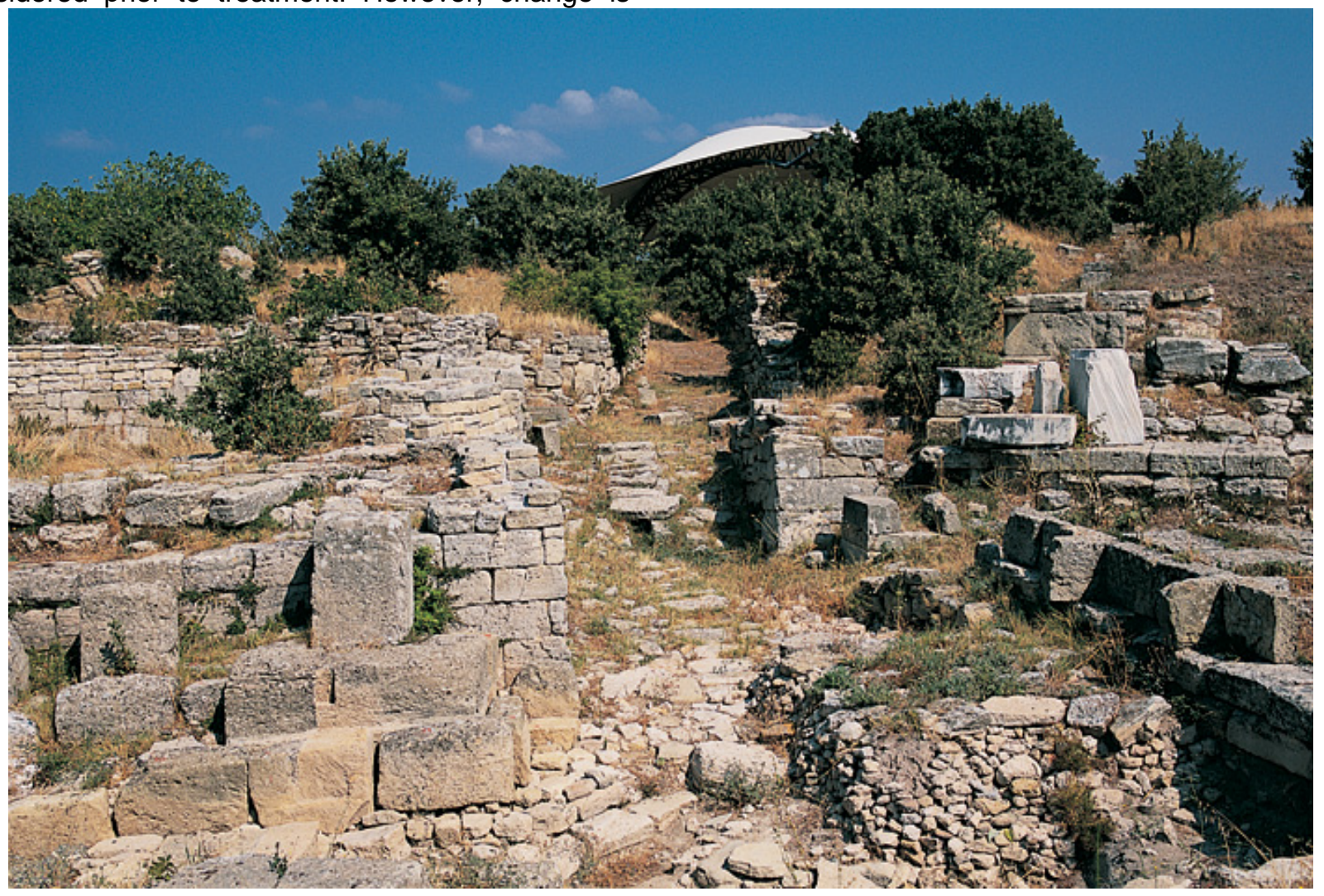

Fig 5. A general view from Troy (Original, 2008)

The physical continuity and the transition of one spatial area into another in the interchange and blending of various landscape phenomena enables the creation of every particular moment. So, landscape variety as one of the foundations of the wealth of experience in the landscape can be significantly reduced as a result of human involvement which strives for unification (8). Besides, the contrasting relief is a foundation not only of diverse land use and as a component of cultural aspect but also for biological diversity. The aspect of experiencing landscape that is many ways considered as the basic and most important feature of landscape should not be neglected. Cultural landscape as mentioned can be a very complex blend of physical and symbolic variance, physical appearance with specific views. Therefore, landscape protection is a moral and ethical issue that must be transferred to future generations although it continuously changes (Figure $6)$. 
Agric. Biol. J. N. Am., 2010, 1(3): 395-401

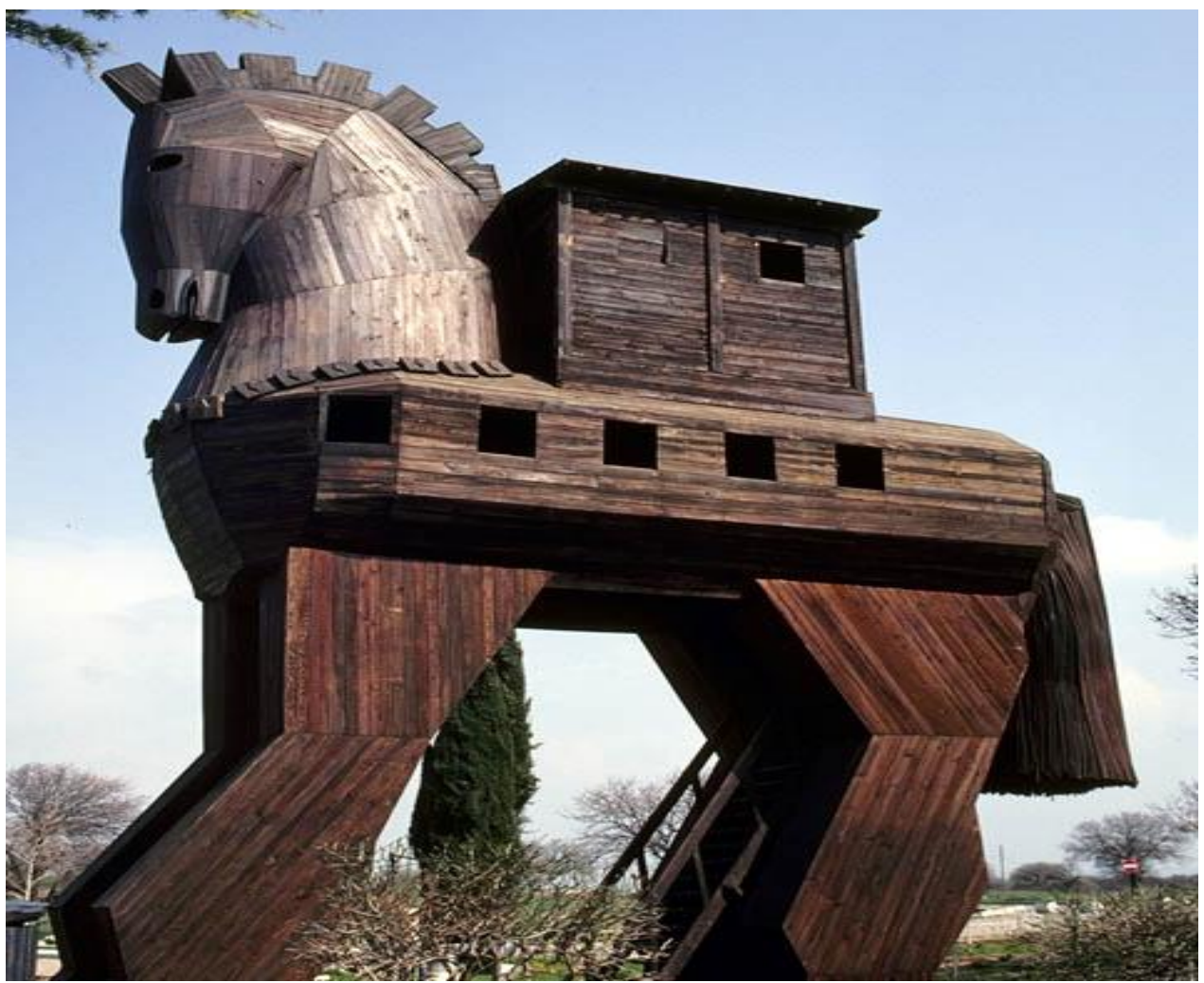

Fig 6. The horse of Troy (Original, 2008)

\section{CONCLUSION}

The landscape quality of Troy has to be considered significant because character defining features such as the remains of the 9 layered antique city and plantation conveys its significance possess historic and cultural integrity. Location, setting of the mound and the construction technique determines the character of the Troy cultural landscape with its unique environmental integrity.

Troy is a cultural landscape compromising an archeological site which is unique for both for the Anatolia and the Dardanelles. The archeological site consists 9 layers of settlement patterns built in different periods one above another reflecting cultural traditions and the physical evidence of its significance and natural features. Besides, the setting also contains component landscapes and features. So, Troy not only has historical and archeological value, but also reveal both global and local information about the history of settlements and human development that is most critical to consider prior to treatment.

There is a balance between change and continuity in all cultural resources. Change is inherent in all cultural landscapes as a result of natural processes, human activities and changing technologies. The dynamic quality of cultural landscapes is balanced by the continuity of distinctive characteristics gained throughout in time.
A preservation plan should be prepared for Troy involving broad array of dynamic variables. So, a comprehensive treatment and management plan with a preservation maintenance strategy should be prepared proposing the conservation of cultural landscapes considering the changes in nature and environment with a management and maintenance plan.

The actual concept in the conservation of cultural heritage is related to the whole built environment and should be seen in the ecological context of the world. It is in fact a socio-cultural problem. Each case must be considered as a whole and evaluated individually. Cultural landscapes consist of different types of properties associated with different values and assets depending on the context; thus every case must be treated differently. The whole archeological site of Troy; all 9 layers should not be considered only in relation to an architectural framework; but also include human values related to its social end economic context. It should be considered in its totality as a coherent whole with its specific spatial organization, natural values and the nearby surrounding. Also the authenticity of the area which have identity, technical and economic value should be kept as it possesses a variety of cultural reflections of the past civilizations. 
On the other hand, some general criteria for the conservation and the improvement of the cultural landscape quality of Troy are as such:

- In the preservation of archeological sites and cultural landscapes, a general policy has to be integrated to a comprehensive national planning program should be adopted and the concept of cultural heritage should be seen in ecological context at national and international scales (7)

- The significance of these natural resources should be based on their cultural associations and from their inherent ecological values

- A landscape preservation plan should be implemented and management strategies must be determined so that, maintenance tasks should be held seasonal or cyclical

- The historic character of the settlement should be preserved. The replacement or alterations of features and spatial relationships that characterize the cultural landscape of Troy should be avoided

- Troy, like the other archeological settlements should be preserved in its original location as a unique cultural resource and should be consolidated to conserve the existing original building material and features that were visually identifiable

- Preservation treatments have to be as simple as the basic maintenance of the existing materials and environmental features. Replacement should be minimized whereas protection, maintenance and repair should be supplied

- The character of the cultural landscape of Troy is defined by its spatial organization, landform, land pattern, its topography, 9 layers of settlement pattern , circulation, vegetation and hard landscape elements, so that should be conserved as a whole combination of these features

- Accessibility is very important for such an archeological site; so the existing circulation pattern has to be preserved as it is and the spatial organization, land patterns, current panoramic view points, scenic pullouts, axial routes, framed vistas should be kept as they are

- Existing vegetation should be identified and preserved. Forest areas, trees, shrubs, dunes and ground covers must be preserved in their present situation. Plant species, endemic plants and local formations in their original size, scale, form and texture qualities must be preserved

- Vegetation serving to protect the archeological site should be kept. Only the vegetation seen in the sub surfaces of archeological assets have to be removed to provide building material from the effects of acid rain

- Vegetation can be also used as adequate barriers in creating either alternative routes or for separating pedestrian and vehicular traffic roads from the archeological sites

- Each archeological site should be recognized as a physical record of its period, place and space organization. Changes creating a false sense of historical development should be avoided; so that Troy and its near environs must be evaluated as a unique case reflecting 9 layers of settlement patterns so that 9 layers of settlement culture in one archeological site in a compact mound which has to be taken into consideration as a sensitive preservation area

- Troy is a geographic area including natural, cultural and historical resources associated with the land formation with a qualified landscape character that must be conserved and transferred to future generations

- The rhythm and the morphological pattern of the surrounding relief should be kept as it is as information giving quality of the settlement. Besides, artificial combinations and building activities should be avoided

- Silhouette reflecting the local character should be respected and protected as it is and traditional building material and construction technique should be preserved as if a rare survivor of archeological sites reflecting the life style of an important period of mankind

As a result, Impressive landscape characteristics and the landscape structure, formal order and harmony, settlement pattern, rhythm, orientation, textural characteristics, its basic structural pattern determined either by relief, topography and original character of the archeological site should be conserved as it is blended with natural elements through in time.

REFERENCES

Akurgal, E., 1985. Ancient Civilizations and Ruins of Turkey from Prehistoric Times Until the End of the Roman Empire, Turk Tarih Kurumu Basimevi, Ankara.

Anonymous, 2009a., http:// en. Wikipedia. Org / wik / Troy* Archeological Troy.

Anonymous 2009b., http:// www. Turktour. com / truva. htm.

Anonymous, 2009c., http:/l www. Havadanbak.com/harabeler/images/truva.

Anonymous, 2009d., http:// www. Ufonet.be/MITOLOJI/Truvagiz35:jpg.

Anonymous,

2009e., http://www.itusozluk.com/img.phb/a0ab02a.

Birnbaum, C., 1996. Guidelines for the Treatment of Cultural Landscapes. U.S. Department of the Interior, National Park Service, Washington D.C

Marusic, J., and Ogrin, D., 1998. Methodological Bases. Regional Distribution of Landscape Types in Slovenia, Ministry of Environmental and Physical Plannig, Ljubiana. 